\title{
Media and psychological effect on the transmissibility of the new coronavirus (SARS-CoV2) using the Rach-Adomian-Meyers decomposition method with non-linear incidence rates
}

\author{
Alejandro León-Ramírez ${ }^{1}$, Oswaldo González-Gaxiola ${ }^{1}$, and Guillermo Chacón-Acosta ${ }^{1}$ \\ ${ }^{1}$ Universidad Autónoma Metropolitana Unidad Cuajimalpa
}

July 5, 2020

\begin{abstract}
In recent decades, the world has experienced several emerging virus outbreaks, among which the most recent compromise the respiratory system and are caused by the SARS-CoV2 coronavirus, H1N1, H5N1 viruses, and the H7N9 virus of the severe acute respiratory syndrome (SARS). In this article, we present epidemiological dynamics based on a SIR-type model with nonlinear incidence rates that reflect the impact of the media and the psychological effects on the spread of the disease. The mathematical model of the problem corresponds to a three-dimensional non-linear ODE system. The Rach-Adomian-Meyers (MDM) decomposition method is used to compute an approximation to the solution of the governing system of non-linear differential equations. The present proposed approach is based on dividing the entire domain into subintervals. In each subinterval, the 12-term MDM solution is sufficient to obtain fairly accurate and convergent results.
\end{abstract}

\section{Hosted file}

Covid-Gax.pdf available at https://authorea.com/users/339915/articles/467037-media-andpsychological-effect-on-the-transmissibility-of-the-new-coronavirus-sars-cov2-using-therach-adomian-meyers-decomposition-method-with-non-linear-incidence-rates 
figures/Hubei-susceptibles/Hubei-susceptibles-eps-converted-to.pdf 
figures/Hubeiexp-susceptibles/Hubeiexp-susceptibles-eps-converted-to.pdf 
figures/Hubei-infectados/Hubei-infectados-eps-converted-to.pdf 


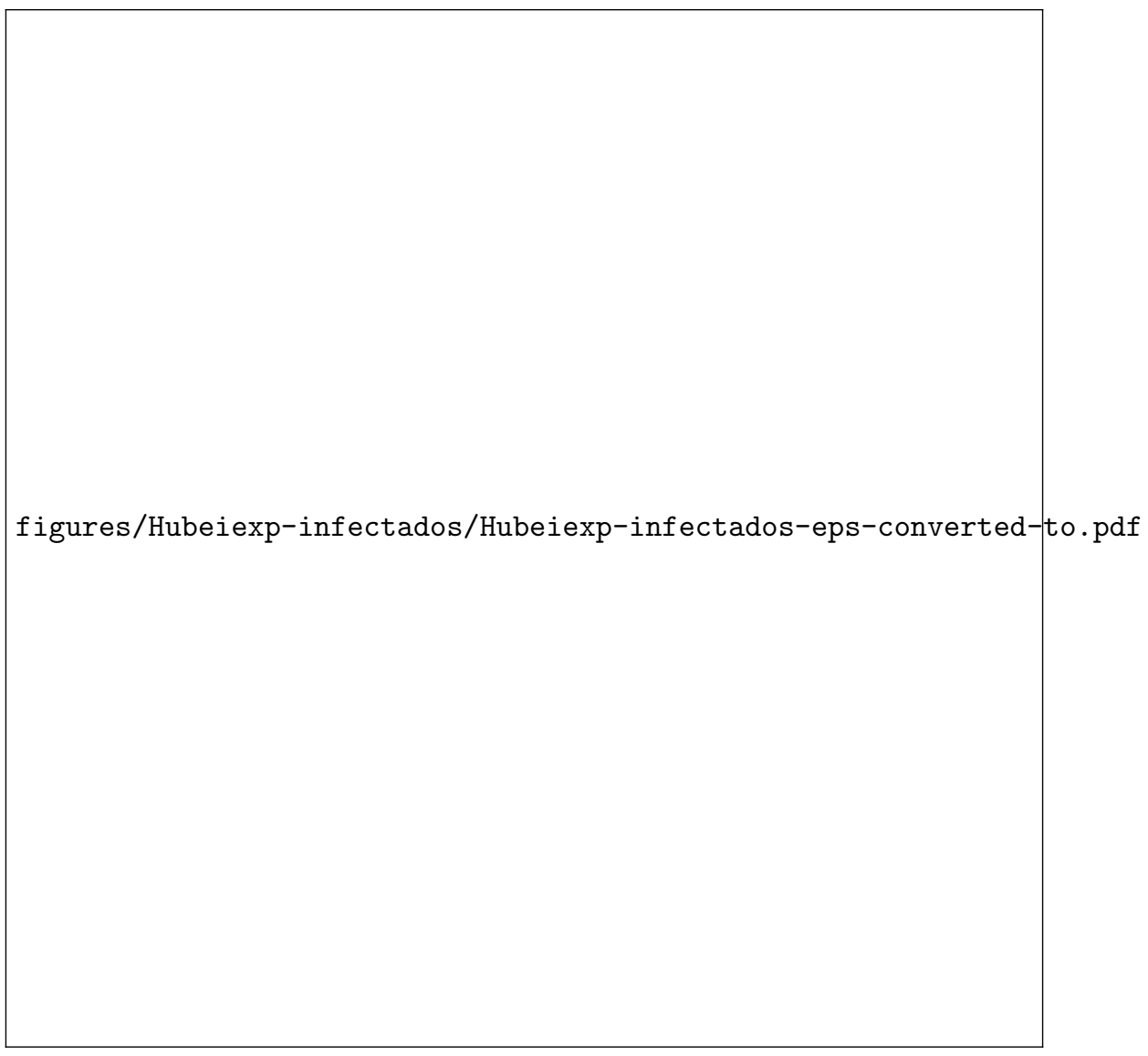


figures/Hubei-recuperados/Hubei-recuperados-eps-converted-to.pdf 
figures/Hubeiexp-recuperados/Hubeiexp-recuperados-eps-converted-to.pdf 
figures/Italia-susceptibles/Italia-susceptibles-eps-converted-to.pdf 
figures/Italiaexp-susceptibles/Italiaexp-susceptibles-eps-converted-to.pdf 
figures/Italia-infectados/Italia-infectados-eps-converted-to.pdf 
figures/Italiaexp-infectados/Italiaexp-infectados-eps-converted-to.pdf 
figures/Italia-recuperados/Italia-recuperados-eps-converted-to.pdf 
figures/Italiaexp-recuperados/Italiaexp-recuperados-eps-converted-to.pdf 
figures/Italia-S2/Italia-S2-eps-converted-to.pdf 
figures/Italiaexp-S2/Italiaexp-S2-eps-converted-to.pdf 
figures/Italia-I2/Italia-I2-eps-converted-to.pdf 
figures/Italiaexp-I2/Italiaexp-I2-eps-converted-to.pdf 
figures/Italia-R2/Italia-R2-eps-converted-to.pdf 
figures/Italiaexp-R2/Italiaexp-R2-eps-converted-to.pdf 